Ann. Zootech., I964, 13 (4), 35I-353.

\title{
CROISSANCE DU POULET ET HEURE DE DISTRIBUTION DES ÉLÉMENTS NUTRITIFS
}

\author{
J. GUILLAUME \\ Avec la collaboration technique de Liliane RoBis. \\ Station de Recherches avicoles, \\ Centre national de Recherches zootechniques, Jouy-en-Josas (Seine-et-Oise)
}

\section{SOMMAIRE}

Chez le Poussin, l'heure de distribution des éléments nutritifs (protéines le matin et aliments non azotés le soir, ou vice versa) a une influence brève mais très marquée sur la croissance, et ceci après un délai variable. Par rapport à une alimentation en mélange, la distribution des protéines le soir permet le plus fort gain poids; la distribution du matin le plus faible. Une inversion compensatrice des phénomènes se produit ensuite.

Le rythme nycthéméral ou circadien auquel sont soumis la quasi-totalité des organismes animaux a une influence marquée sur la plupart, si ce n'est sur la totalité des fonctions et des activités vitales (SrmonneT, I964).

Parmi celles-ci, cependant, les fonctions de nutrition ont été fort peu étudiées. Certes on sait que les secrétions digestives n'ont pas la même intensité au cours de la journée (SrmonNET, Ig64) ; mais on ne sait s'il existe des variations comparables dans l'utilisation du repas en fonction de l'heure de la journée. Afin d'aborder ce problème nous avons effectué trois expériences sur des poussins qui recevaient en deux repas une quantité journalière définie et limitée d'éléments nutritifs. Dans le lot témoin la composition des deux repas était identique ; dans les lots expérimentaux, on rassemblait toutes les protéines dans un repas, l'autre étant protéiprive. L'un et l'autre étaient donnés soit le matin, soit le soir. Les poussins élevés en cages individuelles étaient mis en expérience à 4 ou 5 semaines d'âge et pour une durée de I2 jours dans la première expérience, de 3 semaines dans les deux autres. Leurs repas étaient offerts à 9 heures et à 2 I heures et duraient 2 heures. La ration jour- 
nalière a varié entre $\mathrm{r}_{5}$ et $30 \mathrm{~g}$ /jour selon l'âge des poussins et selon les expériences. Le taux protéique du régime a été de 35 , 55 et $22 \mathrm{p}$. Ioo respectivement dans $1 \mathrm{a} \mathrm{Ire}$, 1a $2^{\mathrm{e}}$ et $3^{\mathrm{e}}$ expérience; les animaux étaient éclairés $\mathrm{I}_{4}$ heures par jour de 9 heures à 23 heures.

Nous avons reproduit sur le graphique I les résultats de $1^{\prime}$ expérience $\mathfrak{n}^{\circ} 3$ (22 p. roo de protéines) particulièrement représentative. Pendant 3 jours les gains de poids des 3 lots sont rigoureusement les mêmes. Après 5 jours, le lot consommant les protéines le soir a une croissance considérablement plus élevée que celui qui les mange le matin $(24,5 \mathrm{~g}$ contre $5,0 \mathrm{~g} /$ animal/jour) : différence très hautement significative $(\mathrm{P}<0,00 \mathrm{I})$. Deux jours plus tard le phénomène s'inverse mais la différence des lots tout en restant hautement significative s'amoindrit. Après quoi elle devient de plus en plus faible et dénuée de sens. Le lot témoin, recevant les mêmes éléments en mélange et en deux repas identiques a un gain de poids intermédiaire entre celui des lots précédents. Son irrégularité ne traduit guère que les fluctuations aléatoires et la variation au cours du temps de la quantité d'aliment journellement allouée.

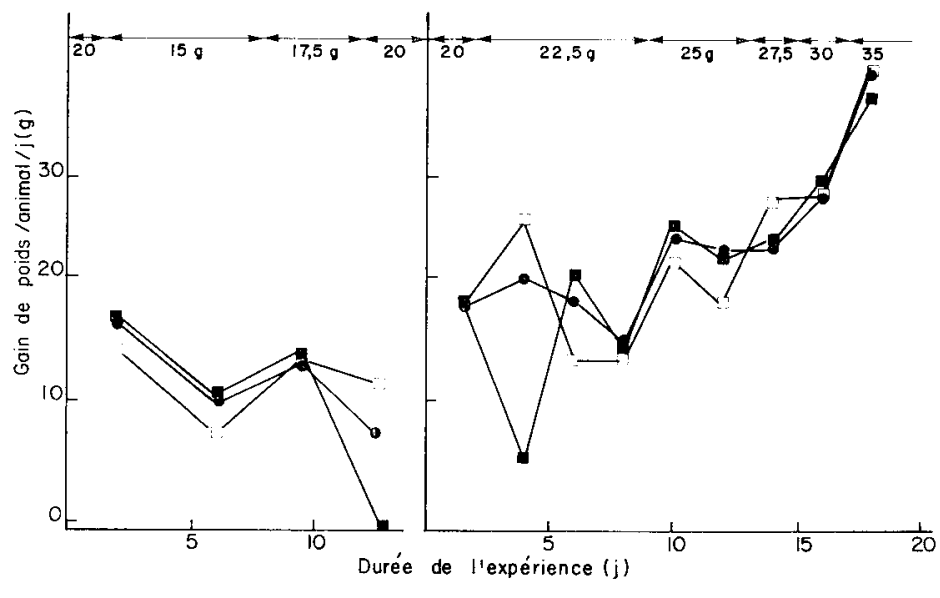

Expérience $n^{0} 1$

Expérience no 3

- Deux repas mixtes.

- Repas protéiné le matin, repas non azoté le soir.

a Repas protéiné le soir, repas non azoté le matin.

Les nombres au-dessus des graphiques indiquent la quantité d'aliment reçue journellement par le poussin (en grammes).

GRAPHIQLE I. - Influence de l'heure de distribution des éléments nutritifs sur la croissance du Pou ssin.

Poussins Arbor Acre de 5 semaines, taux protidique de la ration globale : $35 \%$.

Régime à base de farine de poisson, gluten, amidon et cérélose.
Poussin Arbor Acre de 4 semaines, taux protidique de la ration globale : $22 \%$.

Régime à base de protéines purifiées de soja (supplémentées en méthionine et glycine) et cérélose.

Dans les autres expériences, les mêmes faits ont été retrouvés. Ira différence de croissance entre les lots recevant la protéine le matin au lieu du soir a été d'autant plus marquée que la ration journalière totale était plus riche en protéines. Dans un cas (expérience $n^{\circ}$ I, I5 p. Ioo de protéines, graphique I), cette différence n'est 
apparue qu'après un délai relativement long de 1'ordre de I2 jours. Bien que le gain de poids du lot "protéines le matin " ait été parfois très faible (il était négatif dans l'expérience $\mathrm{n}^{0} \mathrm{I}$ ), le poids des poussins en fin d'expérience s'est toujours retrouvé égal dans tous les lots.

Ces faits peuvent paraitre surprenants, étant donné leur brièveté, le délai variable nécessaire à leur apparition et leur inversion au cours du temps. Nous tenons cependant à répéter que nous les avons observés trois fois. Il s'agit d'un phénomène très bref que nous avons particulièrement bien mis en évidence chaque fois que nous avons pesé les poussins à des intervalles très rapprochés.

La séparation des éléments nutritifs n'a donc pas, sur une période assez longue, d'effet néfaste sur la croissance de l'animal ; par contre. 1'heure de distribution des nutriments a une influence spectaculaire, mais fugace, sur leur utilisation globale.

Reçu pour publication en septembre, r964.

\author{
SUMMARY
}

GROWTH OF CHICENS AND THE IIOLR AT WHICII NLTRILNTS ARE GIVEN

In chickens the time of day at which nutrients are given. proteins in the morning and nonprotein feeds in the evening or vice iersa, has a short but nuarked effect on growth, and the time taken for this effect to show varies. Compared with a complete mised fect, gain in weight is best when the proteins are given in the evening and worst when they are given in the morning. Later there is a compensation change in the phenomena.

\title{
RÉFÉRENCE BIBLIOGRAPHIQUE
}

Simonnet H., ig64. Rythmes et cycles biologiques chez le organismes animaux. Biol. Méd., 53, 266-30... 